\title{
ATELLIE
}

\section{Bacias hidrográficas urbanas: O reflexo da precarização do saneamento em Manaus, Amazonas - Brasil}

\author{
Urban River Basins: The precariousness reflection of \\ sanitation in Manaus, Amazonas - Brazil

\section{Cuencas urbanas: El reflejo de la precariedad del saneamiento en Manaos, Amazonas - Brasil}

Odemar José Santos do Carmo Filho

Universidade Federal do Amazonas

mariojhon.rock@gmail.com

Jean Claudio Campos Oliveira

Universidade Federal do Amazonas

jean.c.campos@hotmail.com

\author{
Adoréa Rebelo da Cunha Albuquerque \\ Universidade Federal do Amazonas \\ adorea27@yahoo.com
}

\begin{abstract}
Resumo
$\mathrm{Na}$ cidade de Manaus, metrópole da Amazônia, graves problemas de saneamento básico, retratam a ineficiência política de gestão sobre a qualidade ambiental das águas urbanas. Neste sentido, a bacia hidrográfica do Gigante, selecionada para este estudo, constituiu a base de uma análise cartográfica e amostragem dessa problemática. Os resultados comprovam que entre $75,1 \%$ a $95 \%$ dos domićlios situados em locais próximos às nascentes dos rios, utiliza a fossa do tipo rudimentar para o esgotamento sanitário. $\mathrm{O}$ uso de poços para o abastecimento de água, em regiões adjacentes a cemitérios e aeroportos, atingiu $100 \%$, gerando insegurança neste tipo de consumo. Sobre a coleta do lixo, enquanto nos domicílios situados à montante $100 \%$ do rejeito é recolhido, nos setores próximos à foz, a coleta é inexistente. $\mathrm{O}$ rendimento per capita de $1 / 2$ até 1 salário, distribui-se espacialmente por toda a área da bacia, denotando sérias desigualdades socioeconômicas. Os problemas ambientais relacionados às questões de saneamento básico transformam-se em riscos à saúde da população que reside nos setores delimitados pela bacia.

Palavras-chave: Hidrografia, Manaus, Saneamento Básico.
\end{abstract}




\begin{abstract}
In Manaus city, Amazonia's metropolis, the serious problems of basic sanitation, point out the management political inefficiency of the environmental quality of the urban waters. In this sense, the Giant's river basin, selected for this study, constituted the basis of a cartographic analysis and the sampling of this problem. The results prove that between $75,1 \%$ to $95 \%$ of the households located in places closer the river source, uses the rudimentary cesspool to the sanitary sewage. The use of wells to the water supply, in regions adjacent to cemeteries and airports, reached $100 \%$, causing insecurity on this type of consumption. About the garbage collection, while in the households located in the upstream have $100 \%$ of the waste is collected, in the sectores close the river mouth, the collect is absent. The per capita income of $1 / 2$ until 1 salary, was spatially distributed throughout the basin area, denoting serious socioeconomic inequalities. The environmental problems related to basic sanitation issues becomes a risk to the health population that resides in sectores delimited by basin.
\end{abstract}

Keywords: Hydrography, Manaus, Basic Sanitation.

\title{
Resumen
}

En la ciudad de Manaos, metrópolis de la Amazonía brasileña, los graves problemas de saneamiento básico, son evidencia de la ineficiente política de gestión en relación a la calidad ambiental de las aguas urbanas. Por tal motivo, la cuenca hidrográfica Gigante, seleccionada para este estudio, fue la base para hacer un análisis cartográfico y un muestreo de este problema. Los resultados muestran que entre el $75,1 \%$ y el $95 \%$ de los hogares ubicados en lugares cercanos a la fuente de los ríos, utilizan un pozo séptico rudimentario para el vertimiento de las aguas residuales. La extracción de aguas provenientes de aljibes, en regiones próximas a cementerios y aeropuertos, alcanzó el $100 \%$, generando inseguridad en este tipo de consumo. En lo concerniente a la recolección de residuos sólidos, se encontró que en los hogares ubicados en la parte alta de la cuenca llega al 100\% mientras que, en los sectores cercanos a la desembocadura, la recolección es inexistente. La renta per-cápita de 0,5 a 1 salario mínimo se distribuye espacialmente por toda la zona de la cuenca, lo que denota graves desigualdades socioeconómicas. Los problemas ambientales derivados de la precariedad en el saneamiento básico, se convierten en riesgos para la salud de la población que vive en los alrededores de la cuenca.

Palabras clave: Hidrografía, Manaus, Saneamiento.

\section{Introdução}

As grandes cidades constituem complexos espaços de inter-relações e de expressão de fenômenos sociais e econômicos e á medida que os espaços residenciais são planejados, selecionam-se gradativamente, os melhores lugares às pessoas de rendas elevadas, evidenciando-se assim, as desigualdades socioespaciais. Em razão deste contexto, remetem-se aos menos favorecidos a ocupação das áreas como fundos de vale, margens de rios e faixas declivosas. Esse tipo de ocupação torna-se vulnerável aos desastres naturais, como inundações e deslizamentos, ademais, ocasiona impactos ambientais e, na proporção do crescimento de aglomerações urbanas, reduz o tamanho das áreas naturais. Convenientemente, o estudo de bacias hidrográficas proporciona a aplicação de uma proposta metodológica, na qual se utiliza uma área delimitada, para o desenvolvimento de uma análise integrada entre os fatores naturais e humanos. 
As bacias hidrográficas tornam-se importantes esferas de análises no que se refere ao planejamento ambiental urbano. Segundo Fortes (2010) este planejamento ambiental urbano envolve pensar a cidade segundo a interação do homem com as condições naturais, compreender a dinâmica da produção espacial, perceber as distintas paisagens e, consequentemente, considerar os seus recursos, no que diz respeito à sua conservação.

Ao se tratar as condições hidrológicas Tucci (2012), menciona que a bacia consiste em uma área de captação natural da água de precipitação, que faz convergir o escoamento para um único ponto de saída, o exutório. Ou seja, as bacias hidrográficas são áreas drenadas pela configuração e morfologia do relevo, cuja água precipitada é direcionada para formar uma rede de canais, tendo um principal receptor e exutório de toda a rede hidrográfica.

O gerenciamento ambiental de bacias hidrográficas se faz necessário, devido à interação existente entre os componentes aquáticos, terrestres e atmosféricos, além da variedade e multiplicidade dos problemas de degradação dos recursos ambientais ocasionados por pressão antrópica (SALLES et al., 2008). Nessa perspectiva, o planejamento ambiental urbano, precisa considerar as bacias hidrográficas urbanas, como importantes células de análise socioespacial, já que são essas bacias, principalmente em grandes cidades, que regulam a drenagem pluvial e a rede geral de esgoto, além da captação de água para consumo (como ocorre em pequenas e médias cidades).

A problemática em questão é a forma de ocupação dentro do perímetro da bacia, e como o meio físico/natural se encaixa como uma das principais variáveis de pesquisa neste campo. O objetivo que norteia a pesquisa é evidenciar os problemas sociais tendo como delimitador a bacia hidrográfica, e em conjunto com a proposta da análise socioambiental, correlacionar os problemas urbanos com os problemas naturais, revelando assim a precariedade vivida no interior das bacias hidrográficas. Para os autores Andreaza e Lanna (2000), definida a área física objeto de gerenciamento como sendo a bacia hidrográfica, a abordagem da questão ambiental pode ser feita sob uma visão sistêmica, a qual pressupõe a exigência de conhecimento integral da região de estudo.

Para elaboração deste estudo foram coletados dados secundários da Plataforma do Governo Federal (Instituto Nacional de Pesquisas Espaciais - INPE) e de Órgãos Internacionais (Serviço Geológico Norte Americano - USGS). Os Modelos Digitais de Elevação foram trabalhados para delimitação da bacia hidrográfica e dos canais. Os dados de natureza socioeconômica, como renda, esgotamento sanitário, abastecimento de água e destino do lixo foram obtidos da Base Censitária do IBGE. A tabulação dos dados permitiu a produção de materiais visuais (tabelas e mapas temáticos) para compreender a distribuição espacial dos fenômenos. 


\section{Área de Estudo}

A Bacia Hidrográfica do Gigante (Figura 1) drena uma área de $22 \mathrm{~km}^{2}$, delimitada administrativamente entre oito bairros descritos a seguir: Ponta Negra, Planalto, Lírio do Vale, Nova Esperança, Redenção, Alvorada, Santo Agostinho e Tarumã. $\mathrm{O}$ canal principal denomina-se Igarapé ${ }^{1}$ do Gigante e suas nascentes situam-se no bairro Tarumã, setor oeste da cidade de Manaus, correspondendo à Área de Preservação Ambiental - APA Parque Linear do Gigante, no setor sul do Aeroporto Internacional Eduardo Gomes. A faixa de desembocadura (outlet) ocorre no rio Tarumã, cuja foz localiza-se no bairro Ponta Negra.

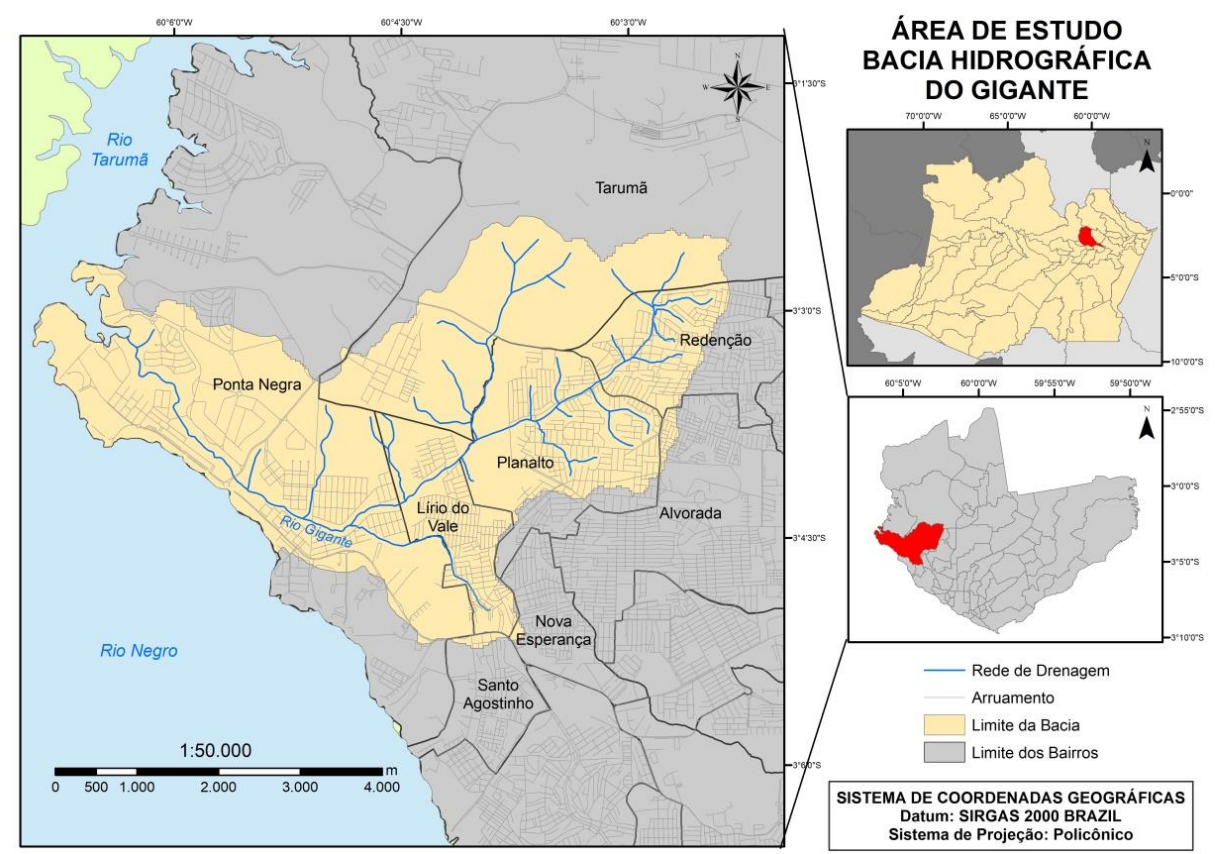

Figura 1: Área de Estudo: Bacia Hidrográfica do Gigante.

Fonte: SEMMAS, 2010; IBGE, 2010; EARTH EXPLORER, 2014. Elaboração: Carmo Filho (2020)

Dentro do perímetro da bacia hidrográfica do Gigante, encontram-se cinco áreas de preservação ambiental, estando três delas sob responsabilidade do município de Manaus, e uma em propriedade privada. A Prefeitura Municipal de Manaus é responsável pelas seguintes áreas e preservação: Área de Proteção Ambiental Tarumã/Ponta Negra; Área de Proteção Ambiental Parque Linear do igarapé do Gigante (Figura 2); Área de Proteção Ambiental Parque Ponta Negra, totalizando 22.892,9 hectares de áreas preservadas pelo município. Além dessas áreas, existe também a

\footnotetext{
1 Palavra que em língua tupi, significa "caminho de canoa", através da junção dos termos ygara (canoa) e apé (caminho).
} 
Reserva Particular do Patrimônio Natural Águas do Gigante, criada em 2008. A tabela 1 apresentada a seguir apresenta as áreas protegidas e o decreto:

Tabela 1: Áreas de Proteção Ambiental na bacia do Gigante.

\begin{tabular}{|c|c|c|}
\hline Áreas Protegidas & Decreto & Área (ha) \\
\hline $\begin{array}{l}\text { Área de Proteção Ambiental do } \\
\text { Tarumã/Ponta Negra }\end{array}$ & Decreto 9.556 de 22 de abril de 2008 & $22.698,8$ \\
\hline $\begin{array}{l}\text { Área de Proteção Ambiental Parque Linear } \\
\text { do igarapé do Gigante }\end{array}$ & Decreto 1.500 de 27 de março de 2012 & 155.1 \\
\hline $\begin{array}{l}\text { Área de Proteção Ambiental Parque Ponta } \\
\text { Negra }\end{array}$ & Decreto 1.501 de 27 de março de 2012 & 39.8 \\
\hline Reserva Águas do Gigante & Decreto 9.645 de 27 de junho de 2008 & 35.1 \\
\hline
\end{tabular}

Fonte: Elaborado pelo Autor, 2020.

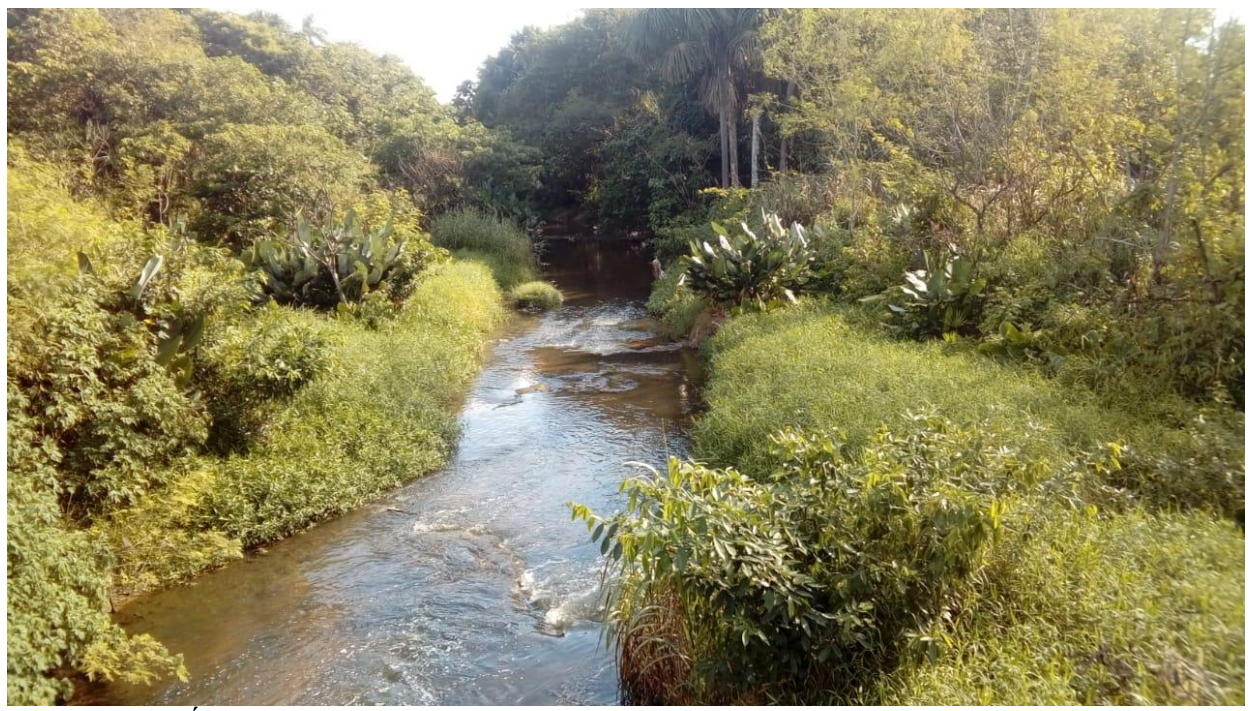

Figura 2: Área de Proteção Ambiental Parque Linear do Igarapé do Gigante, Lírio do Vale, Manaus - AM.

Fonte: Fotografia do Autor (2018).

\section{Resultados e Discussão Aspectos socioeconômicos}

A rede hidrográfica de Manaus distribui-se espacialmente sobre vários bairros, onde o contingente populacional extrapola a área destinada à construção de moradias, 0 que pode ocasionar sérios problemas, tanto aos habitantes como a natureza. A Tabela 2 evidencia os dados demográficos e correlaciona a população com a área de cada bairro. 
Tabela 2: Dados demográficos dos bairros que compõem a bacia do Gigante.

\begin{tabular}{|ccccc|}
$\begin{array}{c}\text { ID } \\
\mathbf{2}\end{array}$ & Bairro & $\begin{array}{c}\text { População } \\
\mathbf{( 2 0 1 0 )}\end{array}$ & Área $\left.\mathbf{( k m}^{\mathbf{2}}\right)$ & $\begin{array}{c}\text { Densidade Demográfica } \\
\left(\mathbf{h a b} \cdot \mathbf{k m}^{\mathbf{}} \mathbf{)}\right.\end{array}$ \\
\hline $\mathbf{3}$ & Alvorada & 64.621 & 5,531 & $11.683,42$ \\
\hline $\mathbf{2 9}$ & Lírio do Vale & 21.534 & 2,140 & $10.062,61$ \\
\hline $\mathbf{3 6}$ & Nova Esperança & 17.696 & 1,478 & $11.972,93$ \\
\hline $\mathbf{4 1}$ & Planalto & 16.283 & 4,292 & $3.793,80$ \\
\hline $\mathbf{4 2}$ & Ponta Negra & 5.007 & 24,131 & 207,49 \\
\hline $\mathbf{4 7}$ & Redenção & 35.166 & 3,002 & $11.714,19$ \\
\hline $\mathbf{5 0}$ & Santo Agostinho & 16.593 & 1,491 & 11,12 \\
\hline $\mathbf{5 9}$ & Tarumã & 28.057 & 39,281 & 714,26 \\
\hline
\end{tabular}

Fonte: Adaptado de SIDRA/IBGE (2010).

Estima-se que existam cerca de 45 mil domicílios na bacia hidrográfica com características diversas. Alguns situados em áreas de extrema vulnerabilidade socioambiental, como o caso na Redenção, outros localizados em condomínios fechados de alto padrão na Ponta Negra. Todos os domicílios com múltiplas características físicas refletem as desigualdades sociais marcantes na bacia do Gigante.

O censo demográfico do IBGE em 2010 realizou um levantamento por agregados de setores censitários ${ }^{3}$ a respeito das condições dos domicílios particulares e domicílios coletivos. Dentro de tal levantamento, constam as seguintes variáveis: abastecimento de água, esgotamento sanitário, destino do lixo, renda mensal per capita e preço da terra. Cada um desses itens foi analisado e será descrito a seguir:

\section{Abastecimento de água}

O IBGE classifica a forma de abastecimento de água nos domicílios a partir das seguintes variáveis: rede geral de distribuição, poço ou nascente na propriedade, água da chuva ou armazenada em cisterna, outra forma de abastecimento.

No primeiro momento apresenta-se o conceito proposto pelo IBGE para a variável rede geral de distribuição, que consiste no domicílio, terreno ou propriedade que apresenta ligação direta à rede geral de distribuição de água.

No que se refere aos levantamentos realizados na bacia hidrográfica do Gigante (Figura 3), os bairros Redenção (47), Alvorada (3), Planalto (41), Lírio do Vale (29), Santo Agostinho (50) e Nova Esperança (36) atingiram 100\% de ligação à rede geral de água. Este resultado apresentou-se como positivo para a situação do saneamento, todavia, nos setores próximos a faixa de desembocadura o quadro de saneamento apresenta-se diferente, com o abastecimento predominantemente de água proveniente de poços.

\footnotetext{
${ }^{2}$ ID - Corresponde ao código apresentado no mapa para identificar os bairros da cidade de Manaus, é uma alternativa utilizada como forma de minimizar textos extensos e indecifráveis no interior dos mapas.

${ }^{3}$ Setores Censitários consistem no menor recorte espacial analisado pelo Instituto Brasileiro de Geografia e Estatística.
} 


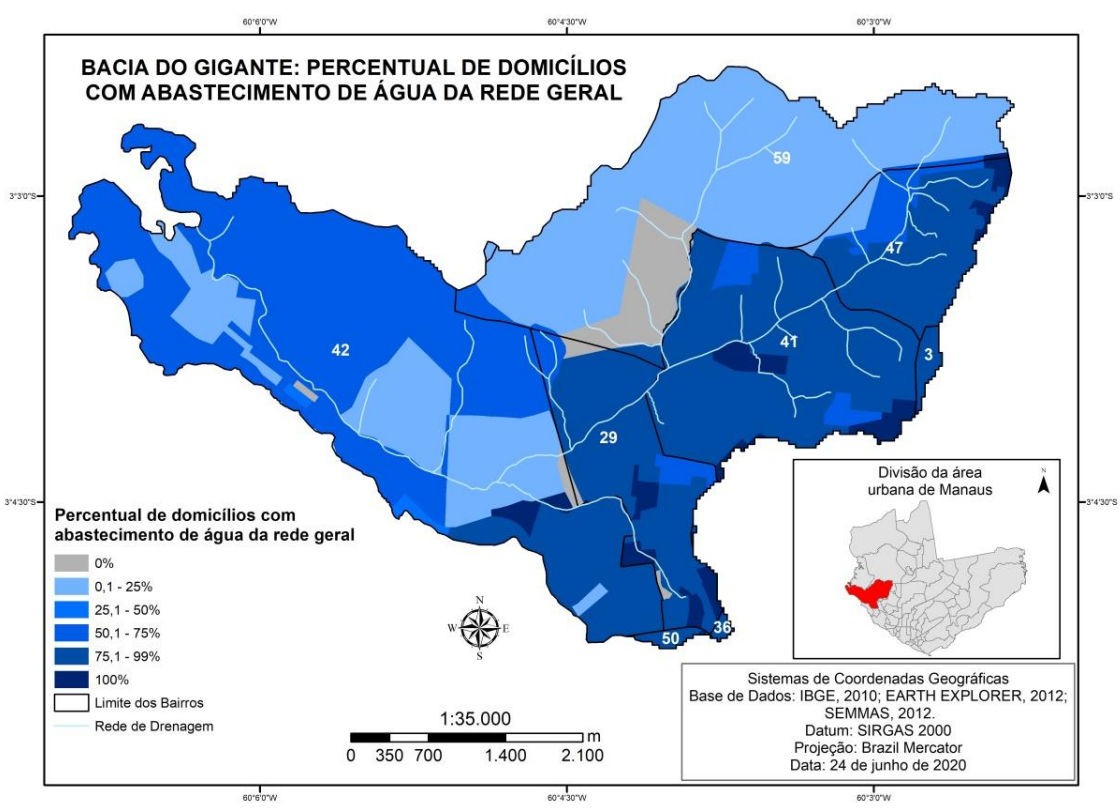

Figura 3: Percentual de domicílios da bacia do Gigante com abastecimento de água da rede geral. Fonte: SEMMAS, 2010; IBGE, 2010; EARTH EXPLORER, 2014. Elaboração: Carmo Filho (2020).

No que concerne a forma de abastecimento por poços ou nascentes na propriedade, a análise dos dados comprovou que na bacia hidrográfica do Gigante o abastecimento domiciliar é 100\% feito por água de poços (Figura 4). As áreas onde este tipo de abastecimento foi mais evidente compreendem o bairro Tarumã (59), o Aeroporto Internacional Eduardo Gomes e o Cemitério Nossa Sra. de Aparecida. Nesses locais, nenhum dos domicílios pesquisados possuem ligação à rede geral de distribuição e são abastecidos predominantemente por poços ou nascentes, detectando-se a completa ausência da rede de saneamento. No alto setor, ao longo dos canais de drenagem e próximo às nascentes, os setores variam entre $0,1 \%$ a $25 \%$ de domicílios. No bairro Ponta Negra (42) quanto mais se aproxima da foz, o percentual se eleva. 


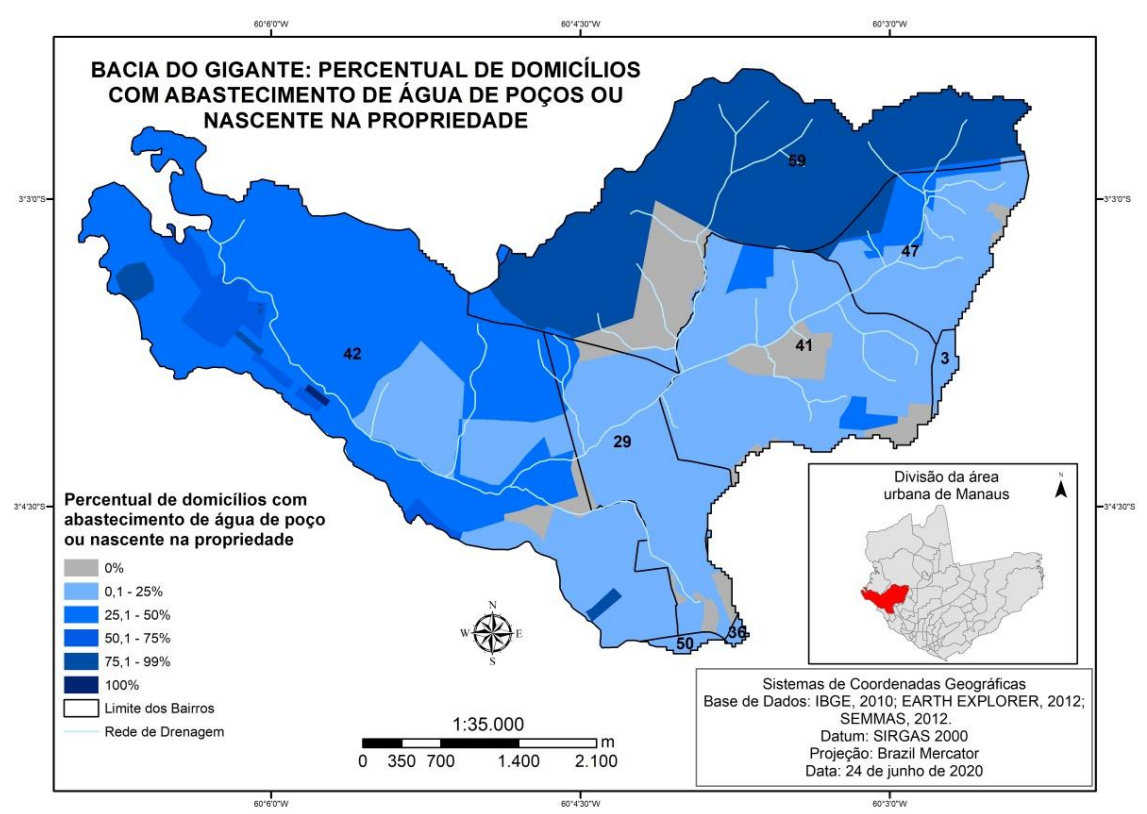

Figura 4: Percentual de domicílios da bacia do Gigante com abastecimento de proveniente de poços ou nascentes na propriedade.

Fonte: SEMMAS, 2010; IBGE, 2010; EARTH EXPLORER, 2014. Elaboração: Carmo Filho (2020)

\section{Esgotamento sanitário}

$\mathrm{Na}$ análise do esgotamento sanitário, o IBGE determina os itens rede geral de esgoto ou pluvial; fossa séptica; fossa rudimentar; a vala; rio, lago ou mar; e outro escoadouro, como variáveis a serem utilizadas para melhor compreensão da qualidade deste serviço.

De acordo com o IBGE (2010), define-se rede geral do esgoto ou pluvial quando a canalização das águas servidas e dos dejetos, proveniente do banheiro ou sanitário, está ligada a um sistema de coleta que os conduz a um desaguadouro geral da área, região ou município, mesmo que o sistema não disponha de estação de tratamento da matéria esgotada. Na bacia do Gigante (Figura 5) há um maior adensamento nos setores censitários nos bairros Lírio do Vale (29), Planalto (41) e Redenção (47), registrando percentuais entre $75,1 \%$ a $98 \%$ dos domicílios conectados à rede geral de esgoto ou pluvial. Na área pertencente ao bairro Tarumã (59) este tipo de esgotamento sanitário é inexiste. 


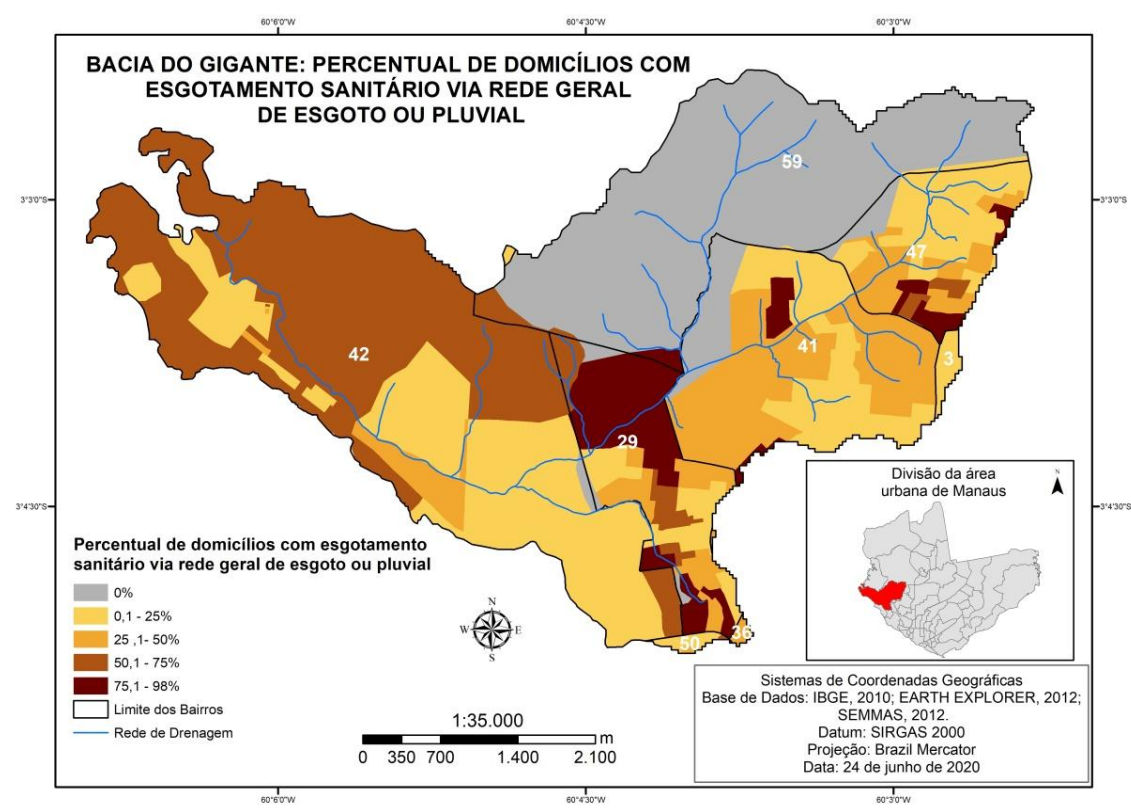

Figura 5: Percentual de domicílios da bacia do Gigante com esgotamento sanitário via rede geral de esgoto ou pluvial.

Fonte: SEMMAS, 2010; IBGE, 2010; EARTH EXPLORER, 2014. Elaboração: Carmo Filho (2020)

No que diz respeito a fossa séptica a descrição feita pelo IBGE á descreve como quando a canalização do banheiro ou sanitário está ligada á uma fossa que passa por processo de tratamento ou decantação, sendo, ou não, a parte líquida conduzida para um desaguadouro geral da área, região ou município. Esse tipo de esgotamento sanitário é bem distribuído espacialmente na bacia hidrográfica (Figura 6), está mais adensado nos bairros Planalto (41) e na porção Sul da Ponta Negra (42), registrando-se percentuais que variam entre $75 \%$ a $97 \%$. Este tipo de esgotamento se estabelece como uma alternativa para a carência de conexão à rede geral de esgoto para tratamento da água. 


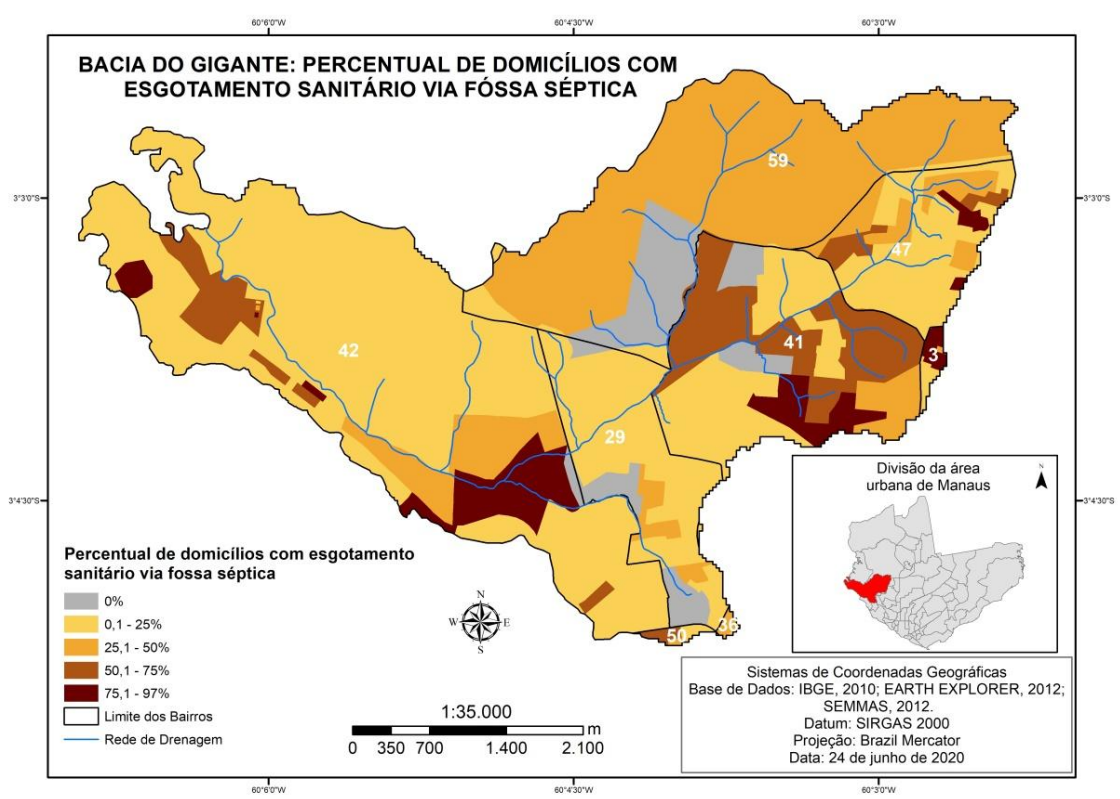

Figura 6: Percentual de domicílios da bacia do Gigante com esgotamento sanitário via fossa séptica.

Fonte: SEMMAS, 2010; IBGE, 2010; EARTH EXPLORER, 2014. Elaboração: Carmo Filho (2020)

O IBGE (2010) conceitua a variável fossa rudimentar como sendo a ocasião em que o banheiro ou sanitário está ligado a uma fossa rústica (fossa negra, poço, buraco, etc.). A fossa rudimentar pode implicar em uma série de problemas de caráter ambiental, como a contaminação do solo e do lençol freático. Esse tipo de esgotamento sanitário ainda é amplamente utilizado para o tratamento e destinação do esgoto em áreas rurais onde se torna a única alternativa quando não há outras tecnologias acessíveis. Apresenta uma solução simples e econômica, sendo por muitas vezes considerada precária já que se trata de um sistema que não garante a separação de forma higiênica de pessoas e suas excretas.

$\mathrm{Na}$ bacia hidrográfica do Gigante ainda é bem elevado o quantitativo de domicílios com esse tipo de esgotamento sanitário, os percentuais elevados variaram entre 75,1 a 95\%. Na Figura 7, observa-se que setores com domicílios que possuem este tipo de esgotamento estão próximos às nascentes da bacia, nos bairros Planalto (41), Redenção (47), Alvorada (3), Ponta Negro (42) e próximo ao canal principal no bairro Lírio do Vale (29). 


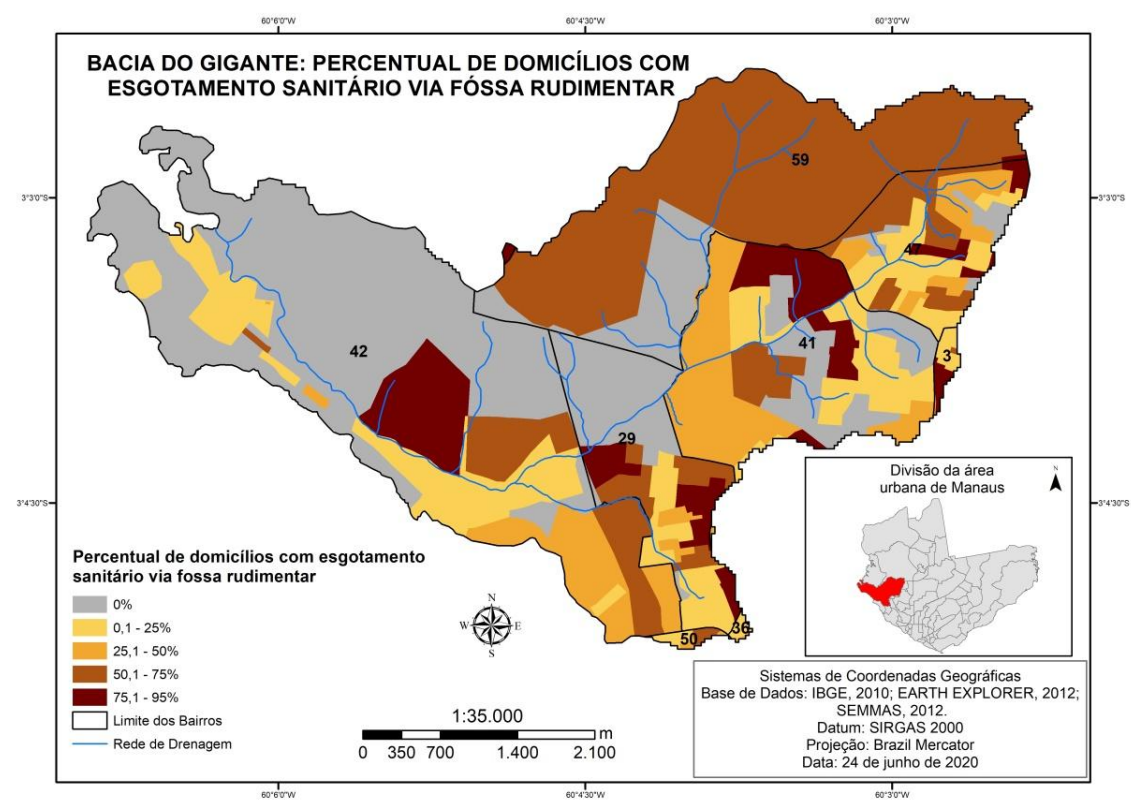

Figura 7: Percentual de domicílios da bacia do Gigante com esgotamento sanitário via fossa rudimentar.

Fonte: SEMMAS, 2010; IBGE, 2010; EARTH EXPLORER, 2014. Elaboração: Carmo Filho (2020)

O termo "vala" foi atribuído ao domicílio que possui o banheiro ou sanitário ligado diretamente a uma vala a céu aberto (IBGE, 2010). Na bacia hidrográfica do Gigante (figura 8), identificou-se um baixo percentual de domicílios com esse tipo de esgotamento sanitário nas residências que se localizam próximos às nascentes e ao canal principal, havendo maior concentração ao Sul do bairro Lírio do Vale (29), com percentuais que variam entre $50,1 \%$ a $64 \%$, próximo às nascentes e demais áreas variando entre $0,1 \%$ a $25 \%$. 


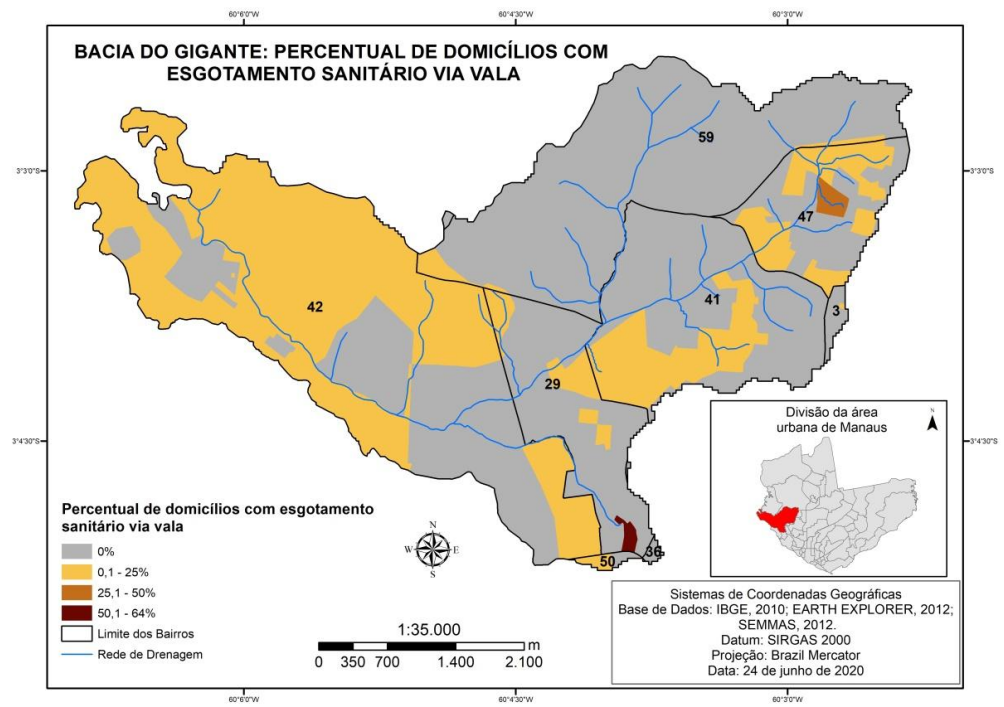

Figura 8: Percentual de domicílios da bacia do Gigante com esgotamento sanitário via vala. Fonte: SEMMAS, 2010; IBGE, 2010; EARTH EXPLORER, 2014. Elaboração: Carmo Filho (2020)

$\mathrm{Na}$ variável seguinte, esgotamento sanitário via rede geral de esgoto, foi possível identificar na bacia hidrográfica do Gigante (Figura 9) que no alto curso fluvial, especificamente no bairro da Redenção (47), 29,1\% a 70\% dos domicílios nos setores no interior desse bairro despejam dejetos diretamente no rio, prejudicando as nascentes e os canais de drenagem.

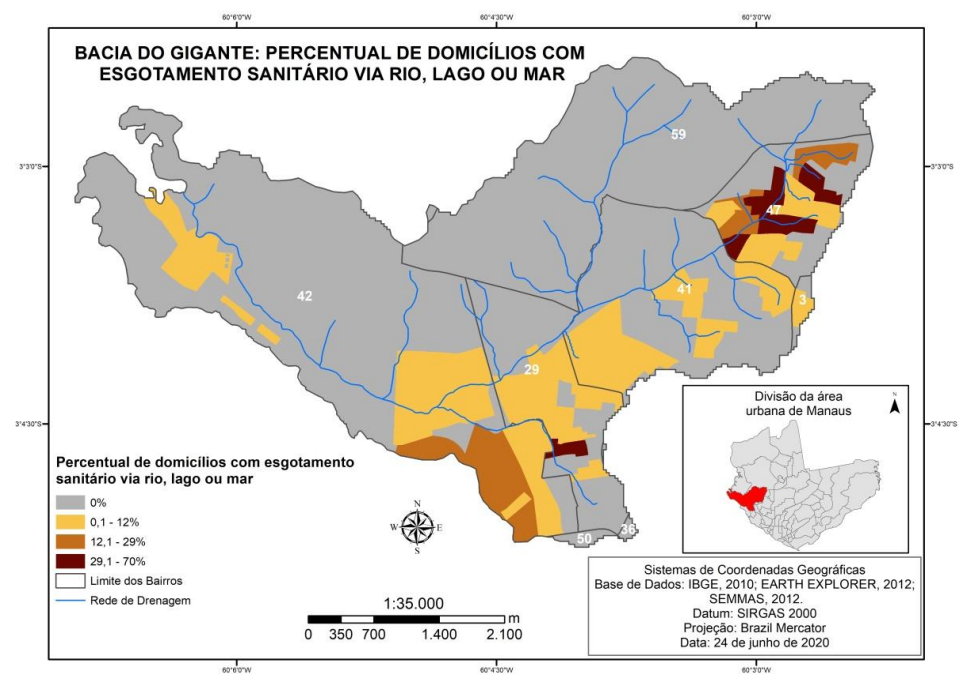

Figura 9: Percentual de domicílios da bacia do Gigante com esgotamento sanitário via rio, lago ou mar. Fonte: SEMMAS, 2010; IBGE, 2010; EARTH EXPLORER, 2014. Elaboração: Carmo Filho (2020) 


\section{Destino do lixo}

Para esta análise foram observadas as seis variáveis utilizadas pelo IBGE que tratam sobre o destino do lixo, estas são apresentadas a seguir: a) coletado diretamente por serviço de limpeza pública ou privada; b) coletado em caçamba, tanque ou depósito fora do domicílio para posteriormente ser recolhido por serviço de limpeza; c) queimado na propriedade; d) enterrado na propriedade; e) jogado em rio, lago ou mar; f) jogado em terreno baldio ou logradouro e, outro destino. Dentre as seis, quatro variáveis serão utilizadas, considerando as observações diretas durante a supervisão de campo.

Com relação a variável lixo do domicílio coletado diretamente por serviço de empresa pública ou privada comprovou-se, de acordo com o mapeamento (Figura 10), que na bacia em estudo, cerca de $90,1 \%$ a $100 \%$ do lixo produzido pelos domicílios é totalmente recolhido.

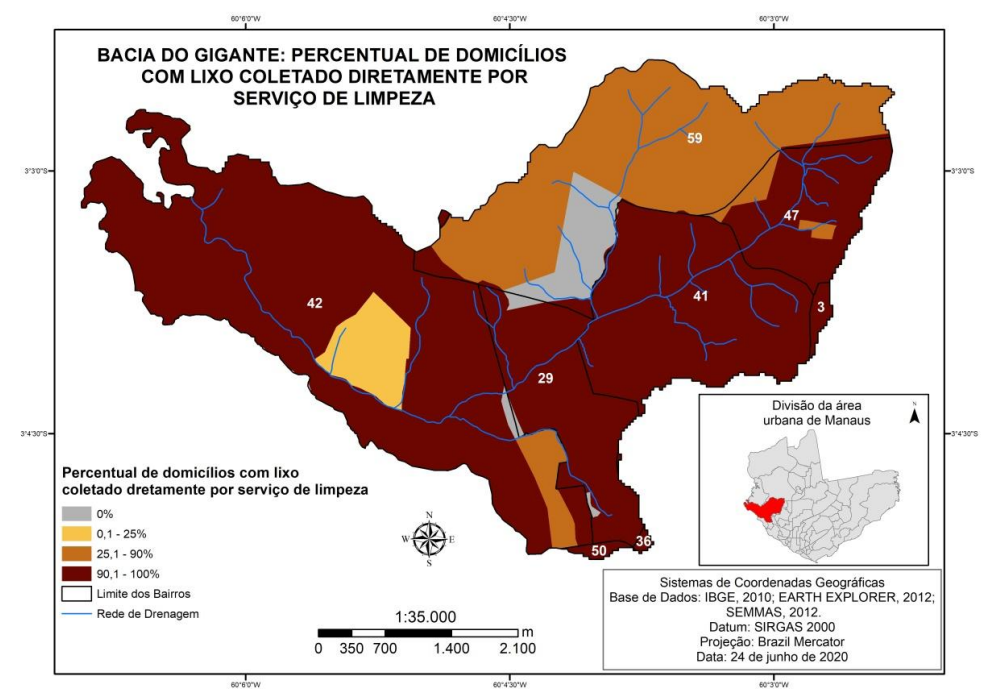

Figura 10: Percentual de domicílios da bacia do Gigante com lixo coletado diretamente por serviço de limpeza.

Fonte: SEMMAS, 2010; IBGE, 2010; EARTH EXPLORER, 2014. Elaboração: Carmo Filho (2020)

No decorrer da análise, quando se tratou a respeito da variável lixo do domicílio depositado em caçamba, tanque ou depósito, posicionado fora da casa, para posteriormente ser coletado por serviço público ou privado, a Figura 11 evidencia que existem vários setores em que apenas $0,1 \%$ a $25 \%$ das residências, possuem depósitos de coleta fora do domicílio. Todavia, identificam-se domicílios em que este percentual atinge zero, tornando a coleta inexistente. Este percentual é um agravante, pois, quando se considera o período chuvoso o lixo despejado inadequadamente pode ser transportado para os igarapés causando riscos de contaminação. 


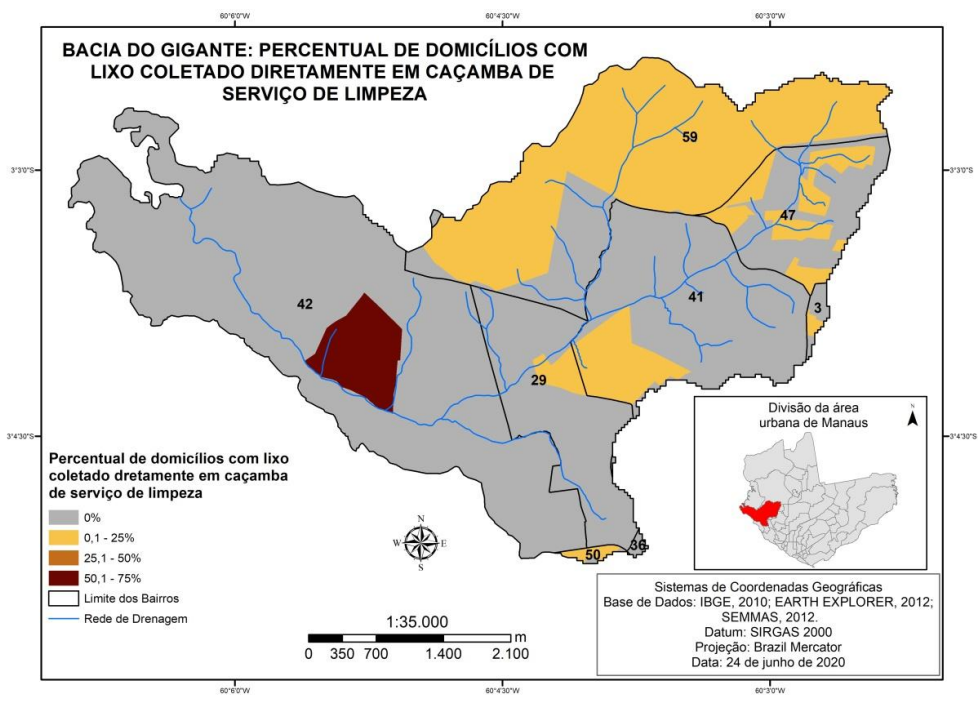

Figura 11: Percentual de domicílios da bacia do Gigante com lixo coletado diretamente em caçamba de serviço de limpeza.

Fonte: SEMMAS, 2010; IBGE, 2010; EARTH EXPLORER, 2014. Elaboração: Carmo Filho (2020)

Em decorrência do rigor e da aplicação de multas previstas por sanções penais da Legislação Municipal, está proibida a queima do lixo. Neste sentido, as informações evidenciadas na Figura 12 revelaram um reduzido quantitativo de setores censitários onde o percentual de lixo queimado na propriedade, não ultrapassou $3 \%$ de domicílios pesquisados.

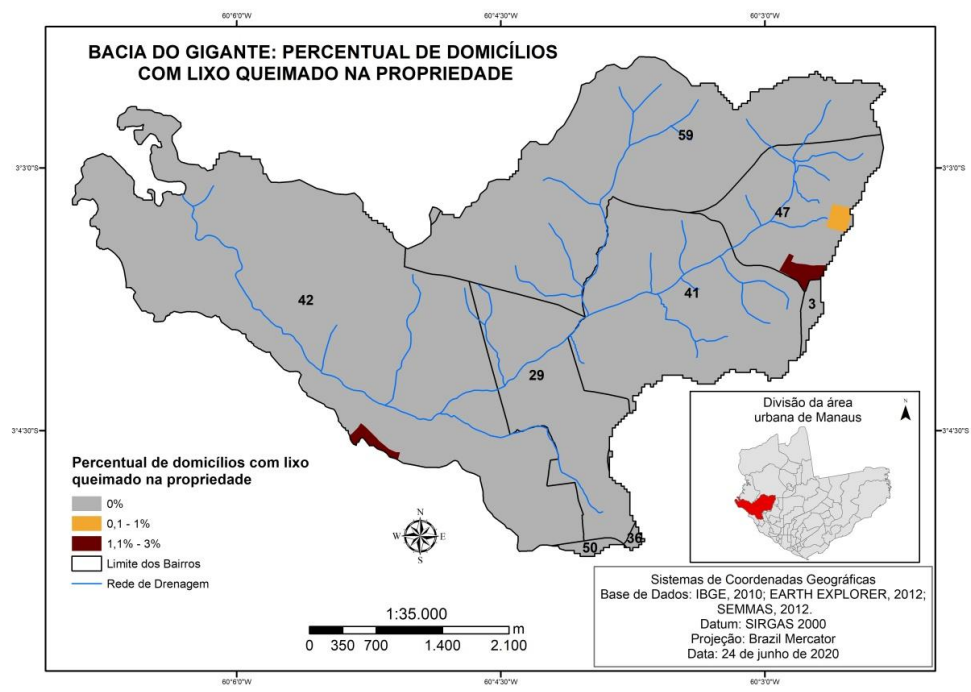

Figura 12: Percentual de domicílios da bacia do Gigante com lixo queimado na propriedade. Fonte: SEMMAS, 2010; IBGE, 2010; EARTH EXPLORER, 2014. Elaboração: Carmo Filho (2020). 
A queima de lixo na propriedade é crime ambiental, as punições aplicadas a esse ato estão respaldadas na Lei $\mathrm{n}^{\circ}$ 9.605/98, que dispõe sobre as sanções penais e administrativas, derivadas de condutas e atividades lesivas ao meio ambiente. No Capítulo II da Aplicação da Lei; Artigo 8 define as penas restritivas: I - Prestação de serviços à comunidade; II Interdição temporária de direitos; III - Suspensão parcial ou total de atividades; IV ${ }^{4}$ Prestação pecuniária; $\mathrm{V}$ - Recolhimento domiciliar.

No que se refere à multa, o Artigo 18 da Lei no 9.605/98 define que a multa será calculada segundo os critérios do Código Penal e, se revelar ineficaz ainda que aplicada no valor máximo, poderá ser aumentada até três vezes, tendo em vista o valor da vantagem econômica auferida. Quanto ao lixo domiciliar despejado em rio, lago ou mar, a Lei ${ }^{\circ} 671$, de 04 de novembro de 2002 regulamenta o plano diretor urbano e ambiental, estabelece diretrizes para o desenvolvimento da cidade de Manaus descreve em seu artigo 10 a coibição desse ato, conscientizando e integrando a participação da população nas ações de proteção dos cursos d'água.

$\mathrm{Na}$ área de pesquisa (Figura 13), o percentual de domicílios que despejam seu lixo nos igarapés não ultrapassa $14 \%$, valor esse registrado principalmente no bairro Ponta Negra (42), vale destacar que este é o bairro onde os preço da terra atinge valor elevado.

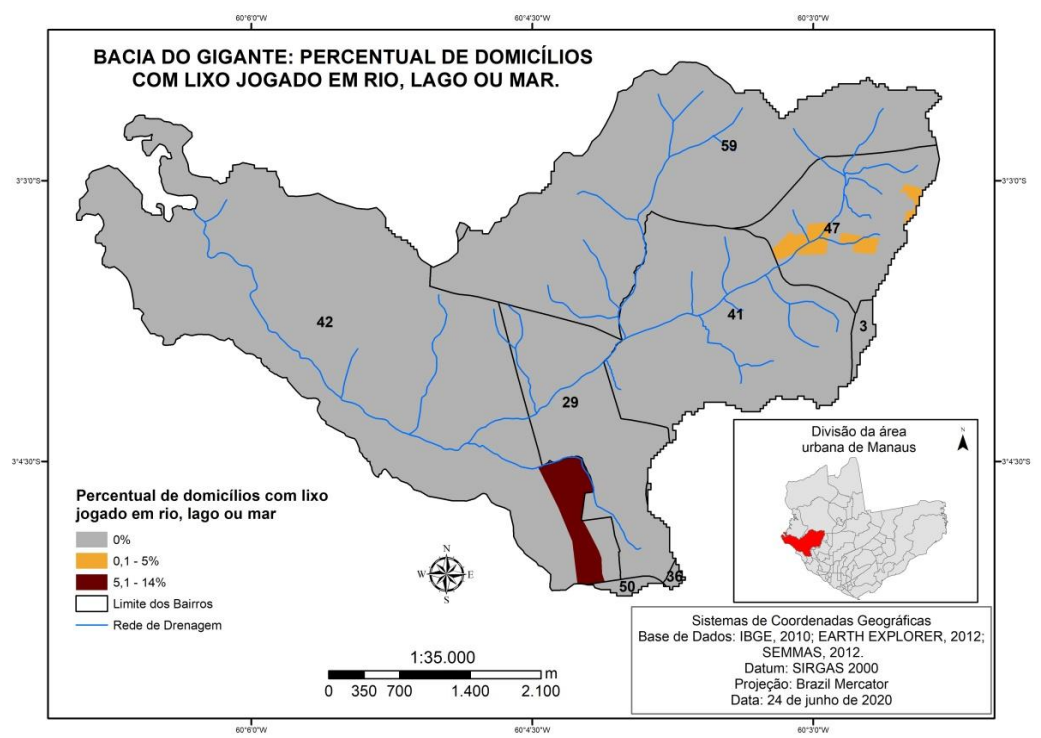

Figura 13: Percentual de domicílios da bacia do Gigante com lixo jogado em rio, lago ou mar. Fonte: SEMMAS, 2010; IBGE, 2010; EARTH EXPLORER, 2014. Elaboração: Carmo Filho (2020)

\footnotetext{
${ }^{4}$ A prestação pecuniária consiste no pagamento em dinheiro à vítima ou à entidade pública ou privada com fim social, de importância, fixada pelo juiz, não inferior a um salário-mínimo nem superior a trezentos e sessenta salários mínimos.
} 


\section{Renda da população}

De acordo com o IBGE (2019) o rendimento domiciliar per capita é a divisão dos rendimentos domiciliares, em termos nominais, pelo total dos moradores. Esses rendimentos são calculados para cada unidade da Federação e para o Brasil, considerando sempre os valores expandidos pelo período anual da pesquisa.

O salário mínimo no Brasil, desde 1940 até os dias atuais passou por vários reajustes a partir dos governantes, às vezes beneficiando, outras, prejudicando a população e a economia. Neste meio tempo, foram utilizadas de diversas moedas: Réis, Cruzeiro, Cruzado e o atual Real.

Em 2010, o Presidente Luiz Inácio Lula da Silva decretou a Lei No 12.255 , de 15 de junho de 2010 (mesmo ano da pesquisa do Censo do IBGE), que dispõe sobre o salário mínimo a partir de $1^{\circ}$ de janeiro de 2010 e estabelece diretrizes para a política de valorização do salário mínimo entre 2012 e 2023 e revoga a Lei no 11.944, de 28 de maio de 2009. O Artigo $1^{\circ}$, inciso I, definiu em 2010, o salário mínimo de R $\$ 510,00$ (quinhentos e dez reais). Na Tabela 3 apresenta-se um demonstrativo sobre o salário mínimo para o período de 2005 a 2015.

Tabela 3: Salário Mínimo no Brasil no período de 2005 a 2010

\begin{tabular}{|cccc|}
\hline Vigência & Valor Mensal & Norma Legal & ${ }^{5}$ D.O.U \\
\hline $\mathbf{0 1 / 0 1 / 2 0 1 1}$ & $\mathrm{R} \$ 540,00$ & ${ }^{6} \mathrm{MP} 516 / 2010$ & $31 / 12 / 2010$ \\
\hline $\mathbf{0 1 / 0 1 / 2 0 1 0}$ & $\mathrm{R} \$ 510,00$ & Lei $12.255 / 2010$ & $16 / 06 / 2010$ \\
\hline $\mathbf{0 1 / 0 2 / 2 0 0 9}$ & $\mathrm{R} \$ 456,00$ & Lei $11.944 / 2009$ & $29 / 05 / 2009$ \\
\hline $\mathbf{0 1 / 0 3 / 2 0 0 8}$ & $\mathrm{R} \$ 415,00$ & Lei $11.709 / 2008$ & $20 / 06 / 2008$ \\
\hline $\mathbf{0 1 / 0 4 / 2 0 0 7}$ & $\mathrm{R} \$ 380,00$ & Lei $11.498 / 2007$ & $29 / 06 / 2007$ \\
\hline $\mathbf{0 1 / 0 4 / 2 0 0 6}$ & $\mathrm{R} \$ 350,00$ & MP $288 / 2006$ & $31 / 03 / 2006$ \\
\hline $\mathbf{0 1 / 0 5 / 2 0 0 5}$ & $\mathrm{R} \$ 300,00$ & Lei $11.164 / 2005$ & $22 / 04 / 2005$ \\
\hline \multicolumn{4}{r}{}
\end{tabular}

Fonte: Adaptado do Guia Trabalhista (2015)

Sobre essa questão o IBGE utiliza algumas variáveis para identificar a renda nominal mensal per capita dos domicílios por setor censitário, sendo estas: a) domicílios sem rendimentos; b) com rendimento nominal mensal domiciliar per capita de mais de 1/2 á 1 salário mínimo; c) mais de 1 á 2 salários mínimos; d) mais de 2 á 3 salários mínimos; e) mais de 3 á 5 salários mínimos; f) mais de 5 á 10 salários mínimos e, aqueles acima de 10 salários mínimo. A população sem rendimentos nominais per capita se refere aos domicílios em que seus residentes não possuem trabalho assalariado, exercendo atividades autônomas, comércios e mercadinhos, borracharia, tabernas, camelôs, dentre outros. As variáveis levam em consideração o valor do salário mínimo no ano de 2010, correlacionando-o aos dados do Censo do mesmo ano.

\footnotetext{
${ }^{5}$ Diário Oficial da União

${ }^{6}$ MP - Medida Provisória.
} 
Analisando o primeiro critério, ou seja, os domicílios sem renda domiciliar mensal per capita, observa-se que na área de realização da pesquisa (Figura 14) esses percentuais são baixos, variando entre $5 \%$ (mínimo) e $27 \%$ (máximo) dos domicílios com setores que atingem o percentual máximo, como no bairro Redenção (27) e pequenos setores na Ponta Negra (42) e Tarumã (59).

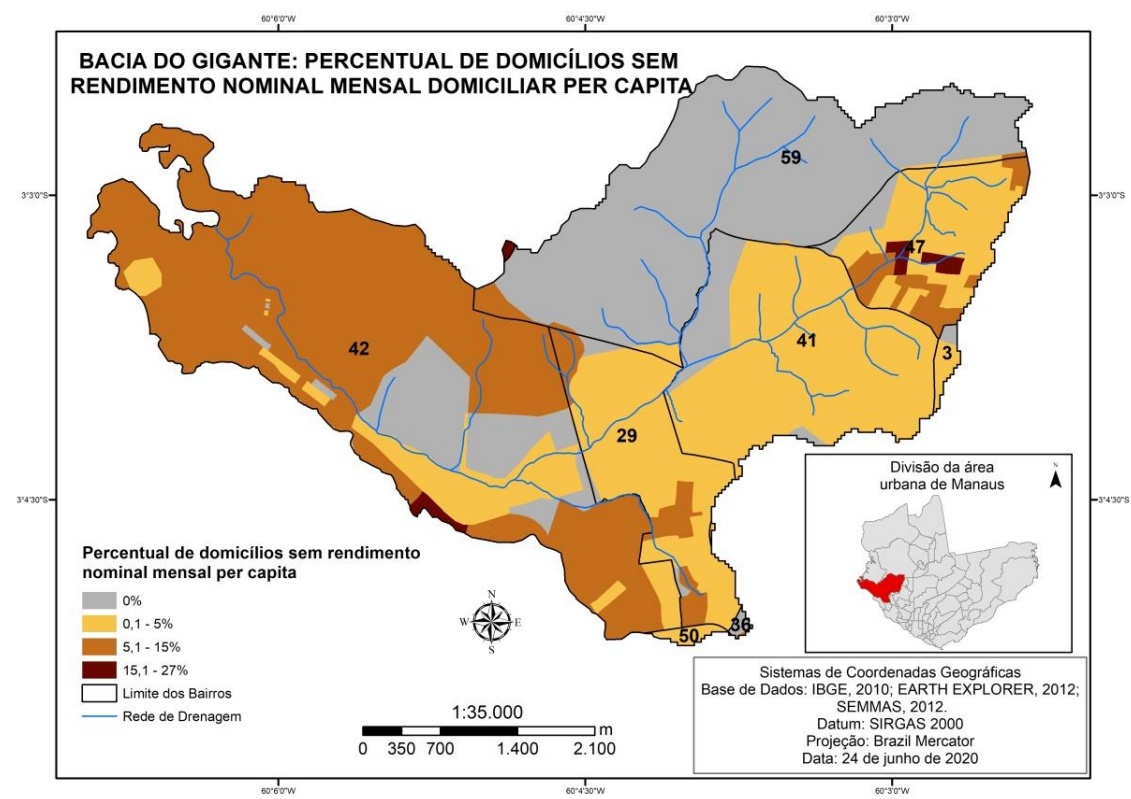

Figura 14: Percentual de domicílios da bacia do Gigante com sem rendimento nominal mensal per capita.

Fonte: SEMMAS, 2010; IBGE, 2010; EARTH EXPLORER, 2014. Elaboração: Carmo Filho (2020)

Sendo o salário-mínimo de $\mathrm{R} \$ 510,00$ no ano de 2010 e, a metade desse valor correspondente ser R \$255,00 observou-se que na bacia do Gigante (Figura 15), os domicílios com esse tipo de rendimento se concentram nos bairros Ponta Negra (42), Redenção (47) e Lírio do Vale (29) com percentuais que variam de 30,1\% a 40\%.

Se for considerado duas vezes $(2 \mathrm{x})$ valor de $\mathrm{R} \$ 510,00$ atinge-se o valor de $\mathrm{R} \$$ $1.020,00$ reais. Isto posto, tornou-se possível identificar que no Igarapé do Gigante (Figura 16) os bairros que concentram essa modalidade de rendimento domiciliar mensal são: Lírio do Vale (29), Planalto (41) e Redenção (47), todos situados no Alto Setor da bacia. Enquanto no baixo setor, esses percentuais variam de $0,1 \%$ e $30 \%$. 
Bacias hidrográficas urbanas: O reflexo da precarização do saneamento em Manaus Odemar José Filho; Jean Oliveira; Andréa Albuquerque

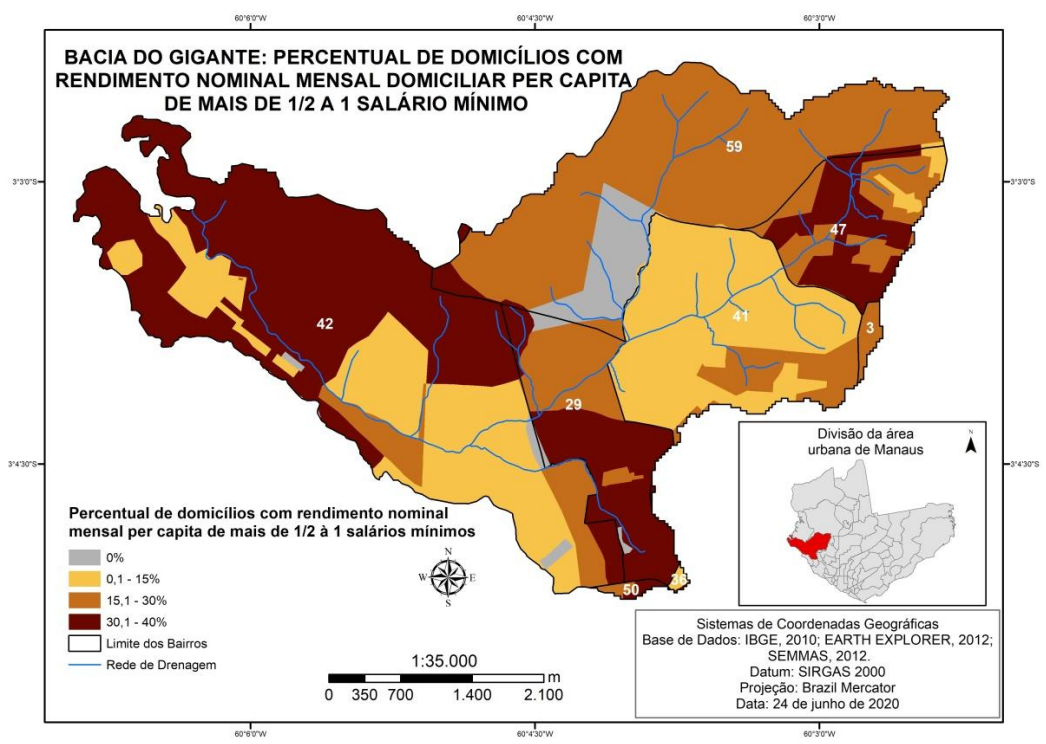

Figura 15: Percentual de domicílios da bacia do Gigante com renda nominal mensal per capita de mais de $1 / 2$ a 1 salário-mínimo.

Fonte: SEMMAS, 2010; IBGE, 2010; EARTH EXPLORER, 2014. Elaboração: Carmo Filho (2020)

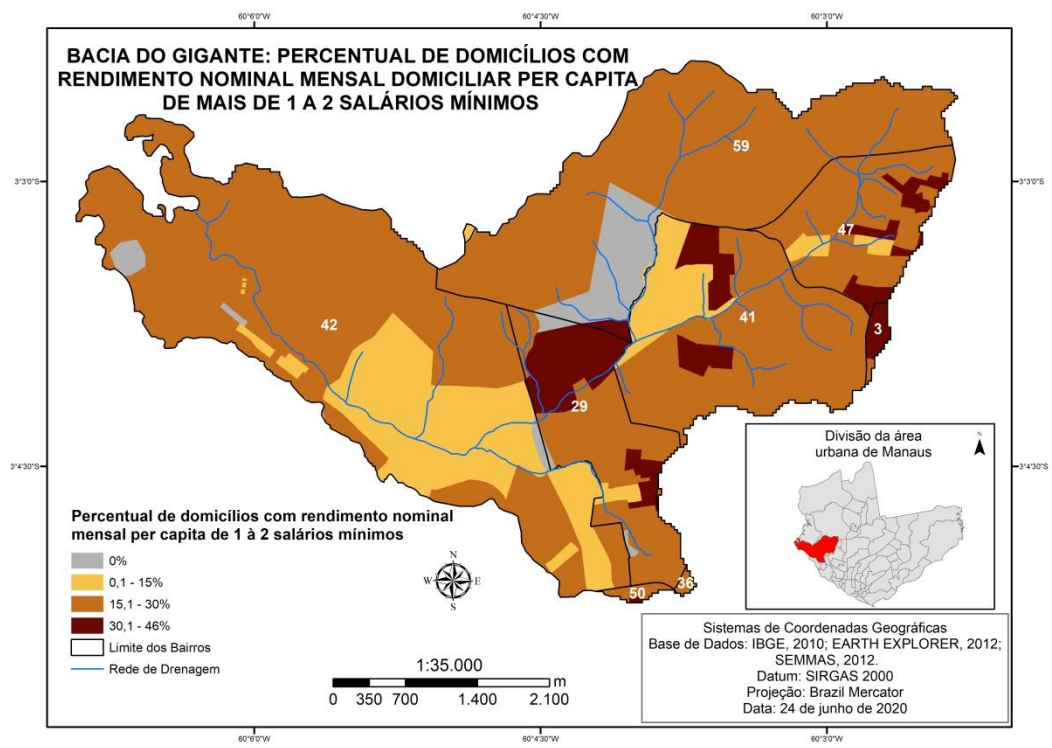

Figura 16: Percentual de domicílios da bacia do Gigante com renda nominal mensal per capita de mais de 1 a 2 salários mínimos.

Fonte: SEMMAS, 2010; IBGE, 2010; EARTH EXPLORER, 2014.Elaboração: Carmo Filho (2020) 
O mapa seguinte (Figura 17), indica os locais onde os rendimentos variam entre mais de 2 salários ( $\mathrm{R} \$ 1.020,00$ reais) até 3 salários mínimos ( $\mathrm{R} \$ 1.530,00$ reais), os bairros do Alto Setor se destacam com percentuais variando entre 10,1 a $22 \%$ sendo estes os bairros Lírio do Vale (29), Planalto (41), Redenção (47) e Alvorada (3). Os mapas até aqui demonstram que no baixo setor e ao longo do canal hidrográfico, concentram-se os domicílios com indivíduos cuja renda é menor que 2 salários mínimos.

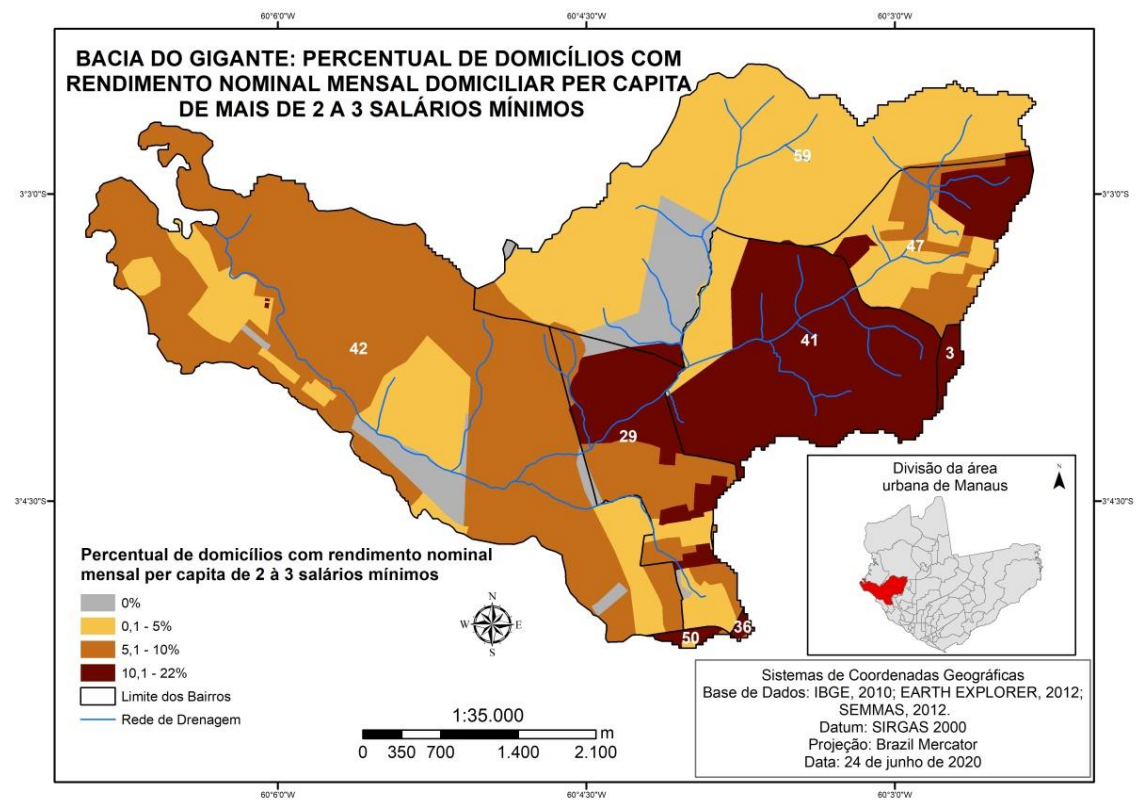

Figura 17: Percentual de domicílios da bacia do Gigante com renda nominal mensal per capita de mais de 2 a 3 salários mínimos.

Fonte: SEMMAS, 2010; IBGE, 2010; EARTH EXPLORER, 2014.Elaboração: Carmo Filho (2020)

No mapa seguinte (Figura 18), visualiza-se os locais onde a renda varia entre mais de 3 ( $\mathrm{R} \$ 1.530,00$ reais) á 5 salários mínimos ( $\mathrm{R} \$ 2.550,00$ reais), destacando-se os bairros: Ponta Negra (42) cuja área do setor censitário corresponder á grande condomínios particulares, Planalto (41) e Alvorada (3), onde o percentual atinge $30 \%$ de domicílios. Ao sul do bairro Ponta Negra (42) e Lírio do Vale (29) esse percentual varia entre os $0,1 \%$ e $5 \%$. 


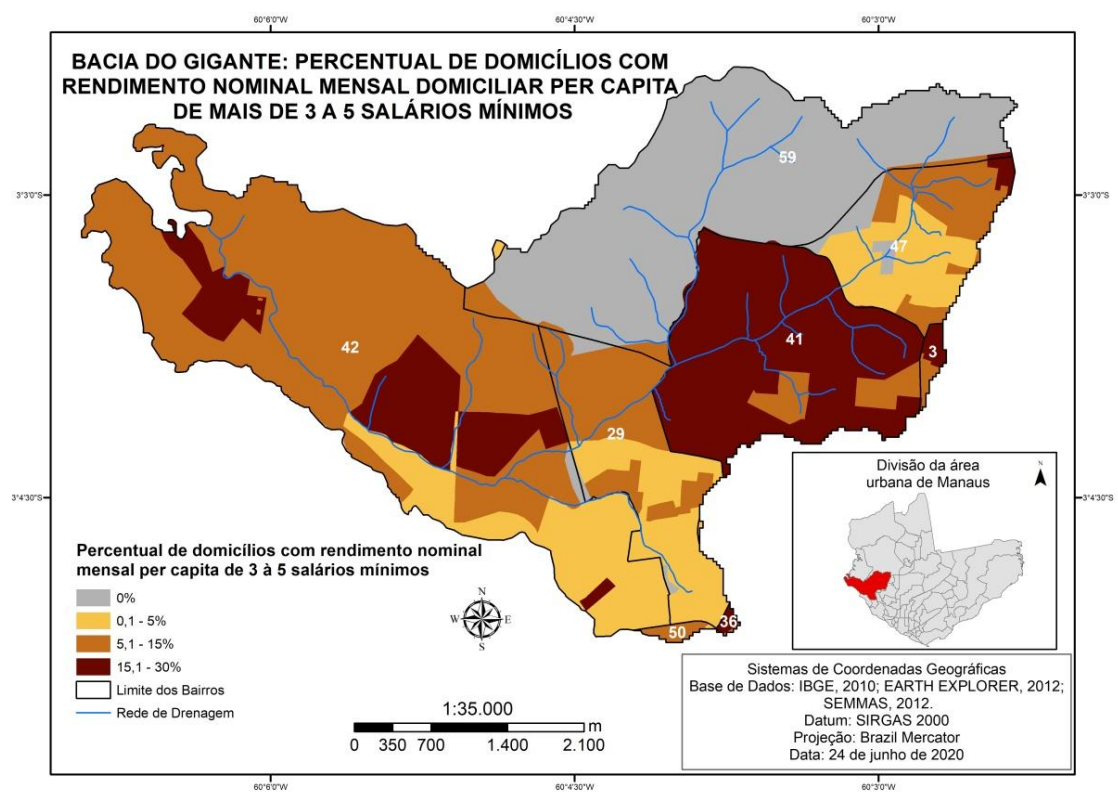

Figura 18: Percentual de domicílios da bacia do Gigante com renda nominal mensal per capita de mais de 3 a 5 salários mínimos.

Fonte: SEMMAS, 2010; IBGE, 2010; EARTH EXPLORER, 2014. Elaboração: Carmo Filho (2020)

As interpretações sobre o quantitativo mensal da renda domiciliar per capita para valores entre $>2$ até salários mínimos - tornaram evidente que no bairro Planalto (41), este percentual atingiu um acréscimo de $10,1 \%$ a $22 \%$, seguido de aumentos de 15,1 a $30 \%$ para rendimentos $>3$ a 5 salários mínimos.

\section{O preço da Terra em Manaus}

A Procuradoria Geral do Município de Manaus (PGM-AM) define valores básicos referentes ao ${ }^{7}$ preço do metro quadrado $\left(\mathrm{m}^{2}\right)$ de determinado terreno, em determinado bairro, sendo estes valores uma referência para avaliação da terra.

No mapa expresso pela Figura 20 são espacializados os valores do preço da terra. Assim, demonstra-se que de forma gradativa, a aproximação da foz, indica que o acréscimo do preço é considerável. Esse acréscimo se deve a supervalorização dos terrenos no bairro Ponta Negra (42), onde existem áreas destinadas ao lazer (praias, academias ao ar livre, calçadão, quiosques, área para eventos), ao turismo (marinas e

\footnotetext{
${ }^{7}$ Como explica PGM-AM (2020) é realizada uma pesquisa de mercado com tratamento estatístico em todos os jornais locais da cidade de compra e venda. Após esta pesquisa é feito uma média desses valores por bairros em $\mathrm{m}^{2}$, no referido bairro. A finalidade deste trabalho estipular um valor por metro quadrado para cada bairro para compra e venda $\mathrm{em}^{2}$ do terreno.
} 
balneários) e residências de alto padrão (Condomínio Riviera de Ponta Negra, Condomínio Bella Ponta Negra, Hotel Tropical Executive, Condomínio Ilha Bela Ponta negra, entre outros.).

A Tabela 4 expõe os valores monetários da terra de 01 de abril a 30 de setembro de 2020. O bairro Ponta Negra é o que possui preço mais elevado, $\mathrm{R} \$ 329,03$, no baixo setor, e no alto setor da bacia temos os bairros Redenção (42) R $\$ 61,32$ e Santo Agostinho (50) R $\$ 66,80$.

Tabela 4: Preço da terra por metro quadrado $\left(\mathrm{m}^{2}\right)$ da bacia hidrográfica do Gigante

\begin{tabular}{|ccc|}
\hline ID & Bairro & Valor $/ \mathbf{m}^{\mathbf{2}} \mathbf{R} \mathbf{\$}$ \\
\hline $\mathbf{3}$ & Alvorada & 166,77 \\
\hline $\mathbf{2 9}$ & Lírio do Vale & 127,44 \\
\hline $\mathbf{3 6}$ & Nova Esperança & 127,44 \\
\hline $\mathbf{4 1}$ & Planalto & 142,19 \\
\hline $\mathbf{4 2}$ & Ponta Negra & 329,03 \\
\hline $\mathbf{4 7}$ & Redenção & 61,32 \\
\hline $\mathbf{5 0}$ & Santo Agostinho & 66,80 \\
\hline $\mathbf{5 9}$ & Tarumã & 129,69 \\
\hline
\end{tabular}

Fonte: Adaptado de PMG - Procuradoria Geral do Município (2020).

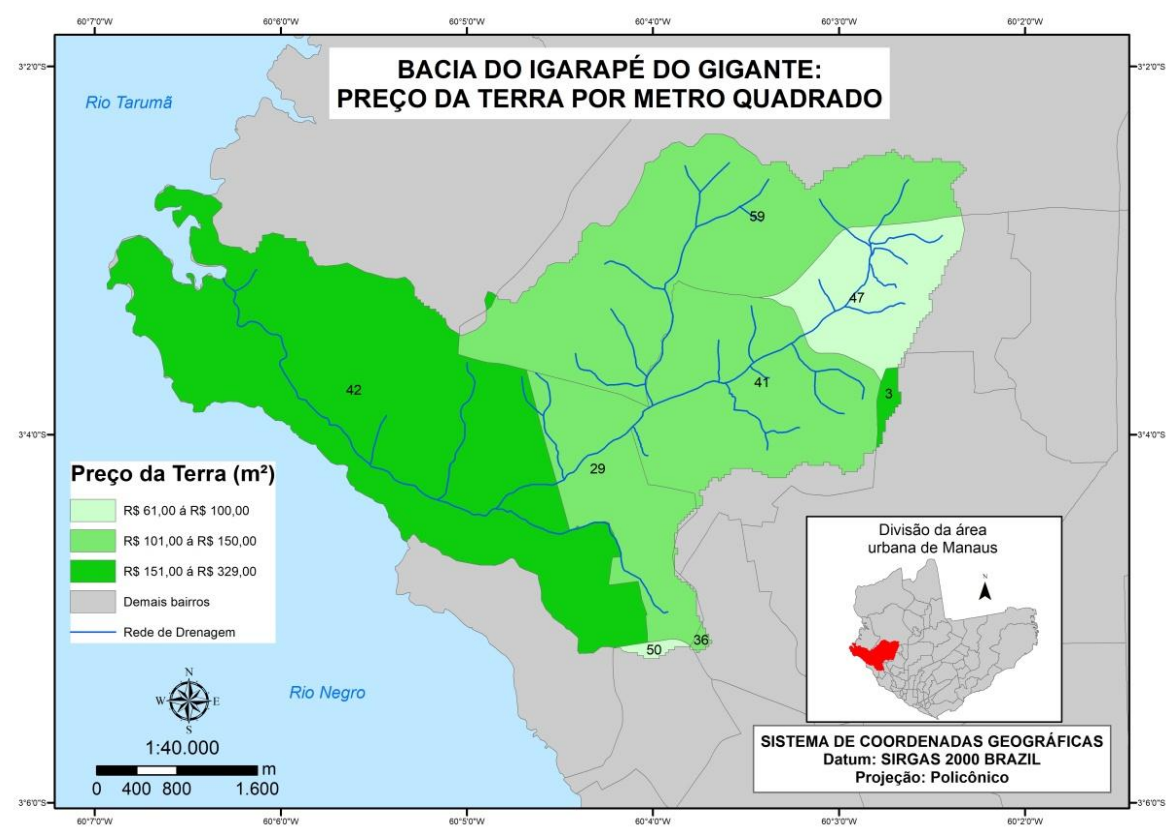

Figura 20: Preço da Terra por metro quadrado na área da bacia hidrográfica do Gigante. Fonte: PGM-AM, 2020; IBGE, 2010; EARTH EXPLORER, 2014. Elaboração: Carmo Filho (2020) 


\section{Considerações Finais}

A partir da análise integrada das variáveis correspondentes ao saneamento básico e a renda da população, verificou-se que $100 \%$ dos bairros são contemplados com o abastecimento de água da rede geral de distribuição. Entretanto, o baixo setor da bacia concentra o maior número de residências onde o abastecimento é proveniente de poços ou nascentes. Esse quadro é grave, quando se equipara a variável esgotamento sanitário, uma vez que em $98 \%$ de domicílios, utiliza-se fossa do tipo rudimentar nos bairros: Planalto (41) e Lírio do Vale (29) ambos situados próximos às nascentes e canais de drenagem. Nos bairros Redenção (47) e Lírio do Vale (29), até 70\% dos domicílios despejam seus esgotamentos sanitários diretamente nos rios. Com estas informações, constata-se que a água consumida por poços e nascentes precisa de monitoramento constante, pois o despejo de dejetos afeta o lençol freático e os canais de drenagem vinda do alto setor da bacia hidrográfica.

A problemática da coleta de lixo também implica problemas ambientais, o descarte incorreto obstrui a rede de drenagem e a canalização, impedindo o fluxo de água proveniente das chuvas e deteriorando as áreas de proteção. Ademais, acarreta em focos de inundações e alagamentos, afetando principalmente quem reside próximo às margens dos igarapés. A partir da análise desta variável, salienta-se que todos os bairros são contemplados com a coleta de lixo, seja pelo serviço público ou privado, entretanto, a forma pela qual o lixo é armazenado fora da propriedade é o mais preocupante. Poucos recortes espaciais da bacia hidrográfica registraram que até $25 \%$ dos domicílios despejam corretamente o lixo em caçambas para serem coletados pelo serviço de limpeza, este percentual indica que na falta de locais específicos para o armazenamento do lixo, este será descartado em calçadas, terrenos abandonados ou queimado na própria propriedade.

Quando analisadas as demais formas de coleta e armazenamento, observou-se que poucas residências queimam o lixo em suas propriedades, são poucos pontos em que menos de $2 \%$ utilizam dessa prática. $\mathrm{O}$ despejo em rio, lago ou mar é presente no bairro Redenção (47) onde concentram setores com até 5\% de domicílios e em um grande recorte do bairro Ponta Negra (42) com até 14\% dos domicílios.

A variável renda permitiu identificar o perfil socioeconômico dos indivíduos, que residem próximos às nascentes e canais de drenagem, bem como evidenciar áreas que necessitam de planejamento urbano para transferir essa população para locais adequados à

habitação. A população sem rendimento mensal per capita se concentra em setores censitários dispersos na bacia hidrográfica, com percentuais que variam em até $5 \%$ de domicílios, entretanto, há uma maior concentração no bairro Redenção (47) com $27 \%$ e Ponta Negra (42) com $15 \%$ de domicílios. O rendimento nominal mensal per capita de $1 / 2$ até 1 salário se concentra nos bairros Redenção (47), Planalto (41) no alto setor e Ponta Negra (42) no baixo setor, com percentuais máximos de $42 \%$ de domicílios. A população estável economicamente, possui primeiramente um rendimento mensal per capita de mais de 1 até 3 salários mínimos concentrando-se em setores censitários dos bairros Redenção (47), Alvorada (3), Planalto (41) e Lírio do Vale (29), no Alto Setor da bacia. Em seguida, os domicílios com rendimento de mais de 3 até 5 salários mínimos se concentram nos bairros Planalto (41) e Ponta Negra (42). 
A partir da análise do preço da terra por metro quadrado, observou-se a tendência de redução do valor, conforme aproximação do alto setor da bacia hidrográfica, sendo a Ponta Negra o bairro mais caro com $\mathrm{R} \$ 329,03$ reais o metro quadrado de terra por conta da supervalorização e a localização estratégica, próximo da orla fluvial. Comprova-se que a população residente nessa bacia, paga caro para adquirir terreno para habitação, havendo pouco retorno dos órgãos competentes em programas de saneamento e planejamento urbano.

A bacia Hidrográfica do Gigante possui um adensamento populacional elevado, com indivíduos residindo próximo aos canais de drenagem, e por conta disso carecem de politicas públicas e de planejamento ambiental. Os mapas evidenciaram problemas sociais em diversos setores da bacia, problemas como despejo incorreto do lixo, precariedade do esgotamento sanitário já que há resquícios de práticas rudimentares (vala, fossa rudimentar), a queima de lixo apesar de legislação que o proíba, e o abastecimento de água a partir dos poços e nascentes na propriedade que muita das vezes se encontra poluída.

A partir das informações expostas é notória a necessidade de projetos na área de Planejamento Territorial Urbano e Ambiental, visto que, em diversas cidades brasileiras, especificamente na cidade de Manaus, o planejamento, principalmente nas áreas da saúde, transporte, lazer e respeito ao ambiente natural, é quase nulo. Esta cidade expandiu-se sem um plano de políticas públicas voltadas para a sociedade e para o meio ambiente, resultando na ocupação de áreas de preservação ambiental, canais hidrográficos urbanos extremamente poluídos e sem vida, baixa qualidade do ar, principalmente nos meses mais secos. Esse conjunto de fatores é uma consequência da má administração pública.

A área em estudo, a bacia do Gigante, não foge da realidade caótica que passa a cidade de Manaus e, algumas cidades do Brasil. Diversos canais afluentes do Gigante se encontram em situação de calamidade oferecendo risco à saúde da população mais vulnerável.

\section{Referência Bibliográfica}

ANDREAZZA, A.; LANNA, A. E. - Contribuição a gestão ambiental da bacia hidrográfica do Arroio do Conde/RS, com ênfase na qualidade das águas superficiais. In: ECOLOGIA, Centro de. Carvão e Meio Ambiente. Porto Alegre. Editora da Universidade Federal do Rio Grande do Sul, 2000. 654 - 664 .

FORTES, M. R. Ambiental urbano em microbacia hidrográfica: uma introdução ao tema. In: ALBUQUERQUE, Adoréa Rebello da Cunha (org.). Contribuições teórico-metodológicas da geografia fisica. Manaus. Editora ADUA, 2010. 193-220. ISBN 978-85-7401-441-8.

MUNICÍPIO, Procuradoria Geral. Valores básicos dos bairros. Disponível em $<$ http://pgm.manaus.am.gov.br/valores-basicos-dos-bairros-r/>. Acessado em 07 de julho de 2020.

MUNICIPAIS, leis. Lei $n^{\circ}$ 671, de 04 de novembro de 2002 - (D.O.M. 05.11.2002 - $n^{\circ}$ 628, ano III). Disponível em $<$ https://leismunicipais.com.br/a/am/m/manaus/lei-ordinaria/2002/67/671/leiordinaria-n-671-2002-regulamenta-o-plano-diretor-urbano-e-ambiental-estabelece-diretrizes-parao-desenvolvimento-da-cidade-de-manaus-e-da-outras-providencias-relativas-ao-planejamento-e-agestao-do-territorio-do-municipio> acessado em 15 de julho de 2020. 
PLANALTO. Lei $n^{\circ}$ 9.605, de 12 de fevereiro de 1998. Disponível em

$<$ http://www.planalto.gov.br/ccivil_03/leis/19605.htm>. Acessado em 29 de junho de 2020.

PLANALTO. Lei $n^{\circ} 12.255$, de 15 de junho de 2010. Disponível em

$<$ http://www.planalto.gov.br/ccivil_03/_Ato2007-2010/2010/Lei/L12255.htm>. Acessado em 03 de junho de 2020.

SALLES, M.; CONCEIÇÃO, F.T.; PEDRAZZI, F. M. J.; SARDINHA, D.; NAVARRO, G.R.B. Avaliação simplificada de impactos ambientais na bacia do alto Sorocaba (SP). REA. Revista de estudos ambientais. v.10, n. 1, p. 6-20, jan./jun. Blumenau - Santa Catarina. 2008.

SEBUSIANI, Helena Rennó Vianna; BETTINE, Sueli do Carmo. Metodologia de análise do uso e ocupação do solo em microbacia urbana. Revista brasileira de gestão e desenvolvimento regional. v. 7, n. 1, p.256-285, jan./abr. Taubaté - São Paulo .2011.

TUCCI, C. E. M. Hidrologia ciência e aplicação. 4ª Edição. Porto Alegre: Editora da Universidade (UFRGS) e EDUSP, 2012.

Odemar José Santos do Carmo Filho

Graduando em Geografia pela Universidade Federal do Amazonas (UFAM).

Rua das Videiras, 57, Cep: 69000-000, Nova Cidade, Manaus - AM.

mariojhon.rock@gmail.com

Jean Claudio Campos Oliveira

Mestrando em Geografia pelo Programa de Pós Graduação em Geografia

(PPGEOG) e Graduando em Geografia pela Universidade Federal do Amazonas (UFAM).

Av. General Rodrigo Otávio Jordão Ramos, 1200, Cep: 69067-005, Coroado I, Manaus - AM.

jean.c.campos@hotmail.com

\section{Adoréa Rebelo da Cunha Albuquerque}

Mestre e Doutora em Geografia Física pela Universidade Federal do Rio de Janeiro (UFRJ). Atualmente é Professora Adjunto da Universidade Federal do Amazonas (UFAM). É membro do grupo de pesquisa em Geografia no Projeto Planejamento Integrado de Reservatórios em Hidrelétricas da Bacia Amazônica com apoio do FINEP, CNPq e MCT. Lidera dois grupos de pesquisa na área de Geografia Física da Amazônia.

Rua Ipixuna, 98, CEP: 69020-050, Centro, Manaus - AM

E-mail: adorea27@yahoo.com

Recebido para publicação em agosto de 2020

Aprovado para publicação em fevereiro de 2021 